\title{
Nataša Kavčič
}

\section{Z margin srednjeveških rokopisov}

\author{
Ključne besede: drolerije, humor, karikatura, iluminirani rokopisi, marginalna \\ dekoracija
}

Naj pojasnim okvir zapisa: v zavesti srednjeveškega človeka sta drug ob drugem bivala vsaj dva vidika sveta, resni in zabavni, in to se jasno zrcali v marginah rokopisov, ki so pravo prizorišče iluzije in spontanega izražanja čustev. Zabavne podobe na marginah zlasti gotskih rokopisov imenujemo drolerije in te (predvsem to velja za zgodnejše primere) imajo pogosto satirično-moralni pomen (Jakobi, 1991, 67). Njihov osnovni namen kljub temu ostaja bralcu zbujati užitek, trdi Carl Nordenfalk, saj nudijo vpogled v vsakdanje življenje v srednjem veku, v svet zabave in sanjarjenja. Drolerije bralca nagovarjajo povsem osebno in pogosto nimajo kaj prida skupnega s sporočilom miniatur, ki ilustrirajo besedilo z versko vsebino (Nordenfalk, 1967, 418).

Najstarejši ohranjeni primer marginalnih upodobitev je prvi volumen dnevnikov papeža Inocenca III. iz vatikanskih arhivov (Vat. Reg. 4), ki med drugim vsebuje korespondenco iz prvih dveh let njegovega pontifikata, od leta 1198 do 1200. Prazne robove papeževih pisem so naselile najrazličnejše podobe in nekaj drolerij se vsebinsko očitno navezuje na zapisane stavke; sličice pojasnjujejo in bralca usmerjajo. To potrjuje splošno mnenje (cf. Randall, 1957 in 1966), da lahko večino srednjeveških marginalnih upodobitev razložimo s pomočjo konteksta, v katerem se pojavijo (cf. Nordenfalk, 1967, 421). V vseh, cerkvenih in posvetnih besedilih, se drolerije bolj razširijo šele po sredini 13. stoletja, kar navadno pripisujemo duhu časa, zaznamovanega s povečanim zanimanjem in občutkom za realizem ter za gotiko značilno naklonjenostjo do satirično-humornih detajlov (Randall, 1957, 8). Na pojav in razvoj marginalne iluminacije je vplival tudi vzpon višjega srednjega razreda, saj so njegovim pripadnikom in aristokraciji bogato okrašeni rokopisi, ki so jih imeli v lasti, pomenili prestiž in estetski užitek.

Razcvet te dekorativne prvine $\mathrm{v}$ 13. stoletju moramo povezati še $\mathrm{z}$ rastočo pismenostjo in s tem povezanimi spremenjenimi vzorci branja (Randall, 1966, 9). Tudi razvoj umetnostnega trga - zlasti v prvi polovici 14. stoletja, ki je čas vrhunca marginalne iluminacije - je dejavnik, ki je imel na razvoj tovrstnih upodobitev precejšen vpliv (Camille, 1992, 151). Pri tem je pomembno, da se geografski okvir, kjer so bile marginalne upodobitve na prelomu v 14. stoletje najbolj pogoste, prekriva 
z enim najbolj trgovsko aktivnih območij na severu Evrope tega časa: tako kulturne kot trgovske izmenjave so potekale med Anglijo in deželami, kot so Artois, Hainaut, Picardy, Flandrija, Brabant in Liège. Vse to so kraji, kjer so nastajali rokopisi s posebej bogatim marginalnim okrasom (Randall, 1966, 8-9).

Vsebinski viri, iz katerih so iluminatorji črpali ideje za marginalne podobe, so precej raznoliki. Največkrat se srečamo s svetopisemsko tematiko; v psaltrih, brevirjih in horarijih so bili kot marginalna dekoracija pogosti novozavezni prizori, še posebej priljubljeni pa so bili prizori iz življenja svetnikov ali prizori Marijinih čudežev. Velikokrat so prisotne teme iz bestiarijev, neredko pa se pojavljajo tudi fantastična bitja iz legend in mitologije (Randall, 1957, 102-104). Iluminatorji so radi vedno znova ponavljali že znane motive, kar ikonografsko bogastvo marginalnih upodobitev nekoliko okrne. Upodabljanje vedno istih elementov je logična posledica uporabe knjig vzorcev ali skicirk, ${ }^{1} \mathrm{v}$ veliki meri pa lahko vsebinsko zaokroženost pripišemo tudi razvoju pridigarstva $v$ prvi polovici 13. stoletja, saj je mogoče ugotoviti številne vsebinske vzporednice med pridigami in marginalnimi upodobitvami (Randall, 1957). Neposreden navdih za izbiro motiva so mojstri iskali v vsebini besedila, ki so ga krasili, veliko vlogo pri tem so imele tudi morebitne historizirane iniciale ali miniature, ki so se znašle na isti strani. Kadar jasne povezave med vsebino zapisanega in marginalno podobo ni, moramo podobe na marginah razumeti zgolj kot quodlibetalne risbe, kasnejše dodatke, ki v sakralnem tekstu nimajo nujno verske vsebine. Predvidevamo lahko, da je imel pri izbiri motivov (še posebej, če je šlo za zasebno naročilo) glavno besedo naročnik rokopisa, seveda pa sta precejšnjo vlogo igrala tudi iluminatorjeva domišljija in smisel za humor (Randall, 1966, 19).

$\mathrm{Na}$ ikonografijo marginalnih upodobitev je bistveno vplivalo tudi dogajanje na trgih srednjeveških mest, ki so se nekajkrat na leto spremenili v prava karnevalska prizorišča in $\mathrm{v}$ središče javnega življenja prinesli razuzdano veseljačenje, sprevrženost in humorne nastope $\mathrm{v}$ nenavadnih kostumih. Četudi so bili tovrstni dogodki redki, so bili v zavesti ljudi živo prisotni skozi vse leto in navdihovali umetnike; podobno svobodo izražanja ter namige na človekovo pokvarjenost in njegove moralne zablode poleg rokopisnih margin (Camille, 1992, 143-146) posredujejo tudi bruhalniki na gotskih katedralah (Camille, 1992, 77-85), rezbarije na t. i. mizerikordijah (Grössinger, 1975, in Camille, 1992, 93-97), v okviru češke stavbne plastike kroga Petra Parlerja pa listne maske na konzolah in kapitelih.

Rokopisne margine so bile prostor za mojstrov bolj spontan individualni izraz, bodisi $\mathrm{v}$ sakralnih podobah bodisi $\mathrm{v}$ prizorih iz vsakdanjega življenja $\mathrm{v}$ povezavi $\mathrm{z}$ družbeno satiro (Randall, 1957, 105). Slednja je v likovni umetnosti pogosto prezrta,

1 Za skicirke in knjige vzorcev gl. Fry (1906-1907, 31-38), Jenni (1978, 139-141), Scheller (1995), Springer (1985, 310-314). 
pa čeprav zelo natančno razkriva stanje duha v okolju, v katerem je satirično obarvano delo nastalo (Menaše, 1995, 41). Družbena satira kot fenomen je nadvse sorodna karikaturi (Kayser, 1981, 37), ki na zabaven način prikazuje vsakdanje življenje, kritično presoja socialne ali politične vsebine ter se norčuje iz človeških hib in norosti. Prav posmeh človeškim zmotam je najpogostejša tema marginalnih upodobitev in zato ne preseneča, da je Jules Champfleury, slavni francoski umetnostni kritik 19. stoletja, gotsko marginalno iluminacijo vključil v svoje delo o zgodovini karikature z naslovom Histoire générale de la caricature (1865-1885) (cf. Camille, 1992, 31).

Prizori, polni humorja in ironije, v rokopisih niso omejeni zgolj na prosto margino, temveč se lahko v reducirani obliki pojavijo tudi kot sestavni del iniciale. V premajhnih notranjih črkovnih poljih tako najdemo ujete velike figure, ki svojo stisko izražajo s pokrčenimi nogami, sklonjeno glavo in z izmučenim izrazom na obrazu; tu in tam pa iniciale postanejo tridimenzionalni objekti, ki jih nad glavo nosijo drobne figure s tako velikim naporom, da z njihovih obrazov obilno kaplja znoj. ${ }^{2}$ Nešteto drobnih risb obrazov na inicialah tekmuje za bralčevo pozornost v rokopisu Moralia in Job iz Nadškofijskega arhiva v Ljubljani (NŠAL 102, rokopis 10). Rokopis je delo pisarja, kaligrafa in iluminatorja Heinricha Aurhayma, ki je leta 1410 na povabilo kranjskega župnika Kolomana von Manswerda bival v Kranju. Pri izdelavi je sodeloval tudi pisar Jakob Chaczpek. Zlasti v drugem delu rokopisa (od fol. 99v dalje), ki je Chaczpekovo delo (Golob, 1995, 362), $\mathrm{v}$ inicialnih risbah začutimo veselje do raziskovanja obraznih potez; nekatere so prav groteskne: iz živalskih gobcev in kljunov nemarno visijo dolgi jeziki, človeški obrazi pa $\mathrm{v}$ prazne margine zrejo $\mathrm{z}$ namrščenim ali spačenim izrazom, se krohotajo, žrejo črke v spodnji vrstici ali pa se jim iz ust vali gost dim. Ta neskončni repertoar humorja in domišljije je trden dokaz svobode srednjeveškega umetnika, kar zanika ustaljeno razumevanje srednjeveške umetnosti kot zgled sistematičnega reda in pobožnosti. Obrazi niso vsebinsko dopolnilo in zdi se, da so risbe po straneh posute brez pravila. Skoraj vsaka črka, ki prestopa meje zrcala, je dopolnjena $\mathrm{z}$ obrazom, kdaj pa kdaj so te drobne podobe tudi vrstično polnilo. ${ }^{3}$ To nam pove, da je bil v času gotike koncept marginalnih upodobitev v bistvu spontan in praviloma ni bil načrtovan vnaprej tako kot ikonografski program velikih iluminacij. Le en obraz v rokopisu $10 \mathrm{iz} \mathrm{NŠAL} \mathrm{ni} \mathrm{del} \mathrm{iniciale} \mathrm{-} \mathrm{ob} \mathrm{zunanji}$ naslonilni črti folija $61 \mathrm{v}$ se razteza $\mathrm{v}$ višino treh vrstičnih enot in strmi v prazno margino. Risba je zaznamovana z zabrisanimi konturami, mehko modeliranimi lici v marelični barvi in rdečimi ustnicami. Glede na slogovno razhajanje $z$ drugimi podobami je ta obraz

2 Za slikovno gradivo z ustreznimi referencami gl. Güntherova, Mišianik (1961, npr. sl. 138 in 146).

3 Dekorativna vrstična polnila so se najprej uveljavila v pariškem knjižnem slikarstvu, lep primer je horarij za Jeanne d'Evreux, ki ga je v letih 1324-1328 iluminiral Jean Pucelle. (Za francosko knjižno slikarstvo 14. stoletja gl. npr. Avril, 1978.) Zaradi slave in velikega vpliva delavnice Mojstra Honoréja, iz katere je verjetno izšel tudi Jean Pucelle, je to domislico prevzelo vse francosko knjižno slikarstvo in kmalu tudi druge šole po Evropi; naše kraje je ta element najverjetneje dosegel pod vplivom iluminatorskih šol praško-dunajskega kroga. 
najverjetneje kasnejši dodatek, s katerim si je, namesto z bolj običajnim »nota« znakom, kateri od bralcev označil še posebej pomembne ali priljubljene vrstice.

$\mathrm{V}$ istem arhivu hranijo fragment Antifonarija (NŠAL 102, rokopis 77), ki je verjetno prišel iz kranjskega župnišča (Höfler, 1966, 98). Gre za delo zgodnjega 16. stoletja (Golob, 2010, 41), od katerega se je ohranilo vsega šestnajst listov. Na tri od štirih kadelnih inicial, zaznamovanih z izrednim kaligrafskim znanjem, so prislonjene karikaturne študije obrazov (slika 1). Zaradi pretirano poudarjenih posameznih obraznih partij se zdijo kot vloge iz komične dramske igre (Golob, 2010, 41), kar zapisano liturgično vsebino močno profanira. Obrazi so izrisani z veliko mero natančnosti in pozornosti do detajlov. Rezultat so nadvse individualizirane podobe, ki jih vrh tega odlikuje še kvaliteta tridimenzionalnosti, ki jo je mojster dosegel s spretno modelacijo v nežni marelični barvi, s katero je dopolnil osnovno risbo, izvedeno $s$ tankim peresom in temno rjavo tinto. Tudi ti obrazi imajo ustnice poudarjene $\mathrm{z}$ rdečo barvo. Ena od velikih kadel na ohranjenih listih je ostala brez tovrstne dekoracije, kar namiguje na to, da so bili obrazi dodani naknadno in zato morda niso delo kaligrafa, ki je rokopis opremil z inicialami. Dosledni slog risb samih pa namiguje na delo ene roke; mojster, ki jih je ustvaril, je bil južnonemškega porekla in morda je prišel iz Nürnberga (Golob, 1990, 113). Na Bavarskem so tudi sicer nastajali rokopisi, polni duhovitih marginalnih upodobitev: v njih lahko vidimo zajce, ki na žaru pečejo lovca, ali pa gosi, ki so premagale lisico, svojo največjo sovražnico (cf. Merkl, 1999).

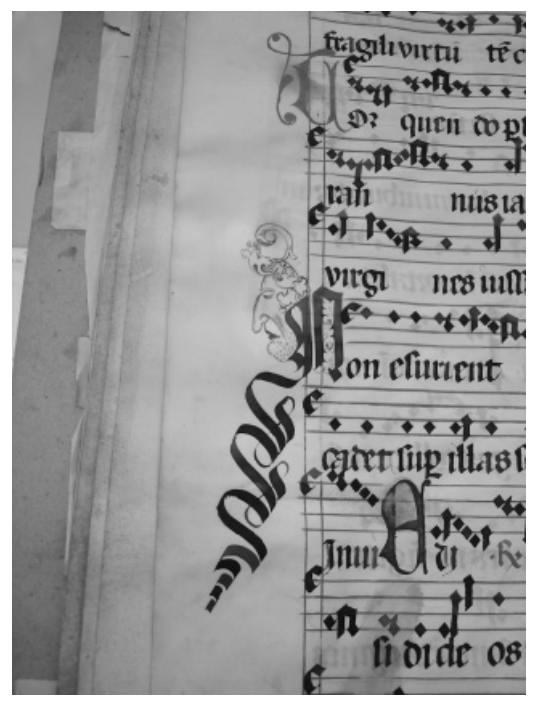

slika 1: Fragment Antifonarija, NŠAL 102, rokopis 77, fol. 168v, Ljubljana, Nadškofijski arhiv vir: foto N. Kavčič 
Iluminatorji so lahko odločitve o dekoraciji sprejemali bolj ali manj samostojno, kar je v zgodnjem srednjem veku povzročilo veliko raznolikost inicial. Kasneje, v poznem srednjem veku, je pojav laičnih mojstrov, ki so se specializirali za določene naloge in bili za svoje delo tudi plačani, pomenil okrnitev inicialne domišljije. Prve črke besedil so odtlej mehansko izdelovali pomočniki v delavnicah, ki so imeli malo možnosti za uveljavljanje lastne individualnosti; mojstrovo ustvarjalnost je do neke mere omejil tudi naslon na knjige vzorcev. Ob koncu srednjega veka sta bila pisar in iluminator ponovno pogosto združena $\mathrm{v}$ eni osebi, ki je ustvarjala iniciale, polne fantazije. Sporočilo, ki ga v sebi nosijo takšne iniciale, je marsikdaj interpretirano $\mathrm{v}$ smislu stremljenja duše $\mathrm{k}$ nebesom ali boja med dobrim in zlim, svetim in posvetnim (Alexander, 1978, 7-27). Meyer Schapiro pa je opozoril, da iniciale v romanskih rokopisih niso bile tipične nosilke moralnega sporočila, temveč jih moramo razumeti zgolj kot pričevanja človeške radovednosti o svetu in odnosa, ki so ga ljudje gojili do spontanega uživanja (Schapiro, 1989, 102).

S podobnimi težavami kot pri iskanju pomena dekoriranih inicial se srečujemo tudi pri interpretaciji marginalnih podob $\mathrm{v}$ gotskih rokopisih. Lilian Randall za razliko od Schapira zagovarja stališče, da bo nadaljnja raziskava razkrila simbolni pomen tudi tistih podob, ki jih trenutno uvrščamo $\mathrm{v}$ kategorijo čiste drolerije in kot take globljega pomena praviloma nimajo. Pri tem poudari še, da so takšne upodobitve razlagale, komentirale ali parodirale spremljajoče besedilo - da so kot marginalne glose, ki lahko imajo za lastnika rokopisa ali iluminatorja prav poseben pomen (Randall, 1957, 102). Pri poskusih interpretacije marginalnih podob pa se moramo zavedati, da nismo omejeni zgolj na alternativi »simbolni in dekorativni pomen « in zato kot dekorativno ne smemo pojmovati vsega, kar pač nima jasne in zlahka prepoznavne (religiozne) vsebine. Kot je opozoril Schapiro, lahko marginalnim upodobitvam pripišemo še kopico drugih pomenov, kot so metafora, parodija ali humor (Schapiro, 1979, 197). Pripisovanje globljega pomena obraznim risbam v rokopisih iz Nadškofijskega arhiva v Ljubljani, kot je denimo družbena kritika ali pa opozorilo na sprevrženost duše, ki se kaže na grdih obrazih, je bržkone pretirano. Obrazi so v srednjeveški umetnosti sicer bili odraz upodobljenčeve duše, vendar jih moramo $v$ tem primeru razumeti kot izraz smisla za humor in naklonjenosti dekorativnemu vpletenih oseb. Tovrstne risbe obrazov se pomenu pravzaprav izmikajo in so v resnici zgolj estetska dopolnila brez didaktičnega pomena ali religiozne simbolike; kot taka zgolj vznemirjajo čute in profano domišljijo bralca.

Pretirano poudarjanje obraznih potez, kot je dolg nos na že tako ali tako podolgovatem obrazu (NŠAL 102, rokopis 77 , fol. 168v) ali pa mesnat nos sredi obraza z napihnjenimi lici (NŠAL 102, rokopis 77, fol. 161v), portretno risbo spremeni $\mathrm{v}$ karikaturo. Za enega od prednikov sodobne karikature veljajo fiziognomične risbe 
Leonarda da Vincija (Enciklopedija Slovenije, 1991, 1). Njegove, pa tudi študije obrazov umetnika po imenu Jacques de Gheyn II (1565-1629), ${ }^{4}$ so nadvse ekspresivne upodobitve, zaznamovane $\mathrm{z}$ neizmerno močjo opazovanja, ki je lastna renesančni umetnostni dediščini; zlasti Leonardove skice lobanj so odličen dosežek umetnikovega raziskovanja $\mathrm{v}$ okviru renesančnega naturalizma. Na verso strani ene od teh risb najdemo umetnikov osnutek za nadaljnjo obravnavo: vključil je obrazne izraze, kot so smeh, presenečenje ali zaspanost, in dodal še obrazne "mehanizme«, kot sta zapiranje oči in vihanje nosnic (Kemp, 1971, 115-121). Vse to so izrazi, ki jih v najrazličnejših rešitvah najdemo že $\mathrm{v}$ srednjeveških rokopisih. $\mathrm{V}$ spretnih in premišljenih risbah obrazov v delih, kot je Antifonarij iz Nadškofijskega arhiva v Ljubljani (NŠAL 102, rokopis 77), je sicer prisotna formatu primerna stilizacija, a jih lahko kljub temu razumemo kot resno napoved realističnih renesančnih študij človeškega telesa.

Izrednega občutka za realistično upodabljanje obrazov pa ne pripisujemo le renesančnim umetnikom, temveč ga začutimo že na prelomu iz 14 . v 15. stoletje, ko so začeli nastajati portreti v dokumentarnem smislu. V ohranjenih skicirkah so obrazi jasno karakterizirani in individualizirani, kar je bila za čas okrog leta 1400 pomembna novost. Pred tem so bile obrazne partije zgolj razporejene po ploskoviti površini in niso dosti prispevale $\mathrm{k}$ posredovanju čustev upodobljene figure - njihovo notranje življenje je bilo izraženo predvsem $\mathrm{z}$ držo telesa in gestikulacijo. V doprsnih podobah na ohranjenih skicirnih listih pa je obrazom namenjena posebna pozornost in $\mathrm{v}$ njih zlahka cenimo občutek mojstrov za mehko modelacijo, prefinjeno opazovanje detajlov in pristno prikazovanje duševnega stanja figur. Takšne risbe sta v zgodnjem 15. stoletju ustvarjala Jacquemart de Hesdin in njegov sodobnik Jacques Daliwe, flamski iluminator, ki je deloval v Parizu. ${ }^{5}$ Flamska rokopisna produkcija je v tem kontekstu sploh pomembna, saj predstavlja najzgodnejši razvoj nizozemske umetnosti v smeri žanra in realizma; v knjigah flamskega izvora tudi najdemo ene najbolj duhovitih kreacij v rokopisnem slikarstvu (Nordenfalk, 1967, 421). Oba mojstra sta znala verodostojno upodobiti človeška čustva, kar je pogosto zahtevalo pretirano poudarjanje delov obraza. Nastale so ekspresivne upodobitve, ki jih težko opazujemo brez misli na karikaturo. Za celo stoletje sta Jacquemart de Hesdin in Jacques Daliwe, skupaj z rokopisnimi mojstri, kot sta Heinrich Aurhaym in Jakob Chaczpek, prehitela gibanje v italijanski umetnosti in postavila trdne temelje za razvoj sodobne karikature.

4 Reprodukcija ene od enajstih ohranjenih risb je objavljena v: Apollo, december 2005, str. 87.

5 Za literaturo gl. op. 1. in Golob (2000). 


\section{Viri}

Ljubljana, Nadškofijski arhiv, Moralia in Job, NŠAL 102, rokopis 10.

Ljubljana, Nadškofijski arhiv, Antifonarij (fragment), NŠAL 102, rokopis 77.

\section{Literatura}

Alexander, J. J. G., The Decorated Letter, London 1978.

Avril, F., Manuscript Painting at the Court of France: the Fourteenth Century (13101380), London 1978.

Camille, M., Image on the Edge. The Margins of Medieval Art, London 1992.

Fry, R. E., On a Fourteenth Century Sketchbook, The Burlington Magazine Vol. X, 1906-1907, str. 31-38.

Golob, N., pod geslom: Iluminirani rokopis, Enciklopedija Slovenije IV, Ljubljana 1990, str. 112-113.

Golob, N., Fragment »Češkega cestopisa « in Orozijev mojster, v: Vita artis perennis. Ob osemdesetletnici akademika Emilijana Cevca (ur. Klemenc, A.), Ljubljana 2000, str. 219-232.

Golob, N., Knjižno slikarstvo v osrednji Sloveniji, v: Gotika v Sloveniji (ur. Höfler, J.), Ljubljana 1995, str. 351-369.

Golob, N., Manuscripta. Knjižno slikarstvo v srednjeveških rokopisih iz Narodne in univerzitetne knjižnice v Ljubljani, Ljubljana 2010.

Grössinger, C., English Misericords of the $13^{\text {th }}$ and $14^{\text {th }}$ Centuries and Their Relationship to Manuscript Illuminations, Journal of the Warburg and Courtauld Institutes Vol. 38, 1975, str. 97-108.

Güntherova, A., Mišianik, J., Stredoveká knižná malba na Slovensku, Bratislava 1961.

Höfler, J., Gorenjski prispevki k najstarejši glasbeni zgodovini na Slovenskem, Kronika 14, 1966, str. 91-100.

Jakobi, C., Buchmalerei. Ihre Terminologie in der Kunstgeschichte, Berlin 1991.

Jenni, U., Vom mittelalterlichen Musterbuch zum Skizzenbuch der Neuzeit, v: Die Parler und der schöne Stil 1350-1400. Europäische Kunst unter den Luxemburgern. Band 3 (ur. Legner, A.), Köln 1978, str. 139-141.

Kayser, W., The Grotesque in Art and Literature, New York 1981.

Kemp, M., »Il concetto dell'anima« in Leonardo's Early Skull Studies, Journal of the Warburg and Courtauld Institutes Vol. 34, 1971, str. 115-134. 
Menaše, L., Humor in satira v slovenski likovni umetnosti, v: Satira Multi. Satira, Humor - Multimedialno (ur. Medved, D.), Celje 1995, str. 41-42.

Merkl, U., Buchmalerei in Bayern in der ersten Hälfte des 16. Jahrhunderts. Spätblüte und Endzeit einer Gattung, Regensburg 1999.

Nordenfalk, C., Drolleries, The Burlington Magazine Vol. CIX, 1967, str. 418-421.

Randall, L., Exempla as a Source of Gothic Marginal Illumination, The Art Bulletin Vol. XXXIX, Nr. 2, 1957, str. 97-107.

Randall, L., Images in the Margins of Gothic Manuscripts, Los Angeles 1966.

Redakcija Enciklopedije Slovenije, pod geslom: Karikatura, Enciklopedija Slovenije V, Ljubljana 1991, str. 1.

Schapiro, M., Marginal Images and Drôlerie, v: Late Antique, Early Christian and Mediaeval Art. Selected Papers, New York 1979, str. 196-198.

Schapiro, M., O estetskih razsežnostih romanske umetnosti, v: M. Schapiro. Umetnostnozgodovinski spisi, Ljubljana 1989, str. 93-127.

Scheller, R. W., Exemplum. Model-Book Drawings and the Practice of Artistic Transmission in the Middle Ages (ca. 900-ca. 1470), Amsterdam 1995.

Springer, P., Modelle und Muster, Vorlage und Kopie, Serien, v: Ornamenta Ecclesiae. Kunst und Kultur der Romanik. Band 1. Katallog zur Ausstellung der SchnütgenMuseums in der Josef-Haubrich-Kunsthalle (ur. Legner, A.), Köln 1985, str. 310314. 


\section{Nataša Kavčič}

\section{The Margins of Medieval Manuscripts}

Keywords: drolleries, humor, caricature, illuminated manuscripts, marginal decoration

Shortly after the mid-thirteenth century, various images began to fill the margins in both religious and secular texts. Many factors influenced the emergence of this type of manuscript decoration, but it has generally been attributed to the revived interest in nature and the Gothic inclination for humorous and anecdotic detail. After highlighting other possible reasons for the occurrence of marginal illumination, this paper introduces two manuscripts from the Archiepiscopal Archives in Ljubljana. The manuscripts show numerous facial drawings affixed to some of the letters. This article addresses how to interpret such drawings and stresses that they do not necessarily function as symbolic images or images with any specific didactic value. Quite the opposite, these drawings seem not to have any meaning and are often merely indications of an illuminator's sense of humor. Because of their exaggerated facial expressions, these drawings could be perceived as the true predecessors of modern caricature. 